\title{
LEE KUAN YEW'S LEADERSHIP LESSONS FROM DEVELOPING SINGAPORE
}

\author{
Alexander Mechitov, University of Montevallo, Montevallo, Alabama, U.S.A. \\ Helen Moshkovich, University of Montevallo, Montevallo, Alabama, U.S.A. \\ Michael J. Grainger, University of Montevallo, Montevallo, Alabama, U.S.A.
}

\section{dx.doi.org/10.18374/IJBS-21-1.4}

\begin{abstract}
Singapore is likely the only country in the world that became independent against its own will. At the time of its inception very few believed it would survive as an independent state. Today Singapore is one of the most developed countries with a thriving economy, a first-class educational system, an envious healthcare system, and one of the highest levels of life. This impressive progress was achieved under the leadership of Lee Kuan Yew - a legendary first Prime Minister of this country, who kept his post for thirty one years and considered a founding father of this young nation. Among other his achievements and likely the most important one was his success in nation building in Singapore by melting three very different ethnic groups with different cultures, religions, and history into one nation. In the first sections, the paper provides a brief outline of Lee's political life and his main accomplishments. The primary attention is paid to the analysis of the main principles and policies Lee used and developed as a leader of Singapore. The paper concludes that Lee's pragmatism and continuous learning from other nations' experiences in addition to his outstanding personal traits were the most important reasons for his remarkable achievements.
\end{abstract}

Keywords: Lee Kuan Yew, Singapore, leadership, nation building. 